\title{
A meta-iodobenzylguanidine scintigraphic scoring system increases accuracy in the diagnostic management of pheochromocytoma
}

\author{
D Cecchin, F Lumachi ${ }^{1}$, M C Marzola, G Opocher ${ }^{2}$, C Scaroni ${ }^{2}$, P Zucchetta, \\ F Mantero ${ }^{2}$ and F Bui
}

Nuclear Medicine Service, Department of Diagnostic Medical Sciences, School of Medicine, University of Padua, Via Ospedale 105,35128 Padua, Italy
${ }^{1}$ Endocrine Surgery Unit, Department of Surgical and Gastroenterological Sciences, School of Medicine, University of Padua, Padua, Italy
${ }^{2}$ Division of Endocrinology, Department of Medical and Surgical Sciences, School of Medicine, University of Padua, Padua, Italy

(Requests for offprints should be addressed to D Cecchin; Email: diego.cecchin@unipd.it)

\begin{abstract}
As observed by other authors, normal adrenal medullary tissue frequently gives an apparently positive meta-iodobenzylguanidine (MIBG) scan in cases studied using ${ }^{123}$ I-MIBG and less frequently ${ }^{131}$ I-MIBG. The aim of this study was to assess the usefulness of a scoring system, based on different uptakes of the radiopharmaceutical, to improve the accuracy of ${ }^{123}$ I-MIBG scintigraphy in patients with either adrenal or extra-adrenal pheochromocytomas. Charts from 67 consecutive patients (29 males and 38 females, median age 48 years, range 14-80 years) with suspected pheochromocytoma (either sporadic or familial: multiple endocrine neoplasia (MEN) 2a, MEN2b, Von Hippel-Lindau, neurofibromatosis type 1) who underwent ${ }^{123}$ I-MIBG scintigraphy (scans acquired 4-24h after injection) from 1991 to 2004, were independently reviewed by two experienced nuclear medicine physicians using liver uptake as a reference (scores: 1, uptake absent or less than the liver; 2, equal to the liver; 3 , moderately more intense than the liver; 4, markedly more intense than the liver). Interfering medications were discontinued for the appropriate time before MIBG injection. Histological data were obtained for all patients who underwent adrenalectomy. Scintigraphies were classified as positive using the following criteria: extra-adrenal focal uptake, adrenal enlargement together with non-homogeneous uptake and adrenal uptake more intense than the liver (score 3-4). After surgical resection, as confirmed by histological findings and long-term follow-up (range 1-14 years, average 9.25 years), 43 patients were considered true positives using the proposed scoring system, 20 were true negatives, four were false negatives and none was false positive. In conclusion, the proposed scoring system demonstrated high specificity (100\%), sensitivity $(91.5 \%)$ and accuracy $(94 \%)$ in the management of pheochromocytoma. Positive predictive value and negative predictive value were $100 \%$ and $83.3 \%$ respectively. Normal adrenal tissue uptake was correctly discriminated from pheochromocytomas in 18 out of 20 patients, with adrenal uptake equal to the liver (grade 2), using the proposed cut-off level.
\end{abstract}

Endocrine-Related Cancer (2006) 13 525-533

\section{Introduction}

At present, the high spatial resolution of morphologic modalities (computed tomography (CT) or magnetic resonance imaging (MRI)) leads to an increasing number of incidentally discovered adrenal masses. Nearly $25 \%$ of pheochromocytomas are discovered incidentally (Lenders et al. 2005). The functional meaning of these masses often remains uncertain, especially if the mass is small with low levels of catecholamine secretion (Taïeb et al. 2004) and where plasma-free metanephrine measurement is not available (Eisenhofer et al. 1999). In the case of an epinephrine-secreting pheochromocytoma, 
MIBG adds little to the pre-operative evaluation of the sporadic adrenal mass identified by CT or MRI associated with a positive biochemical test. On the other hand, MIBG is crucial in revealing extraadrenal uptake and metastatic localization of pheochromocytomas. It is also useful in revealing bilateral uptake. Furthermore, it has been suggested that, in a rare group of patients, ${ }^{123}$ I-MIBG, accumulating in intracellular vesicles via the monoamine transporter, may confirm the presence of a tumor even when biochemical tests are negative or doubtful (Hanson et al. 1991). The finding of high levels of plasma free normetanephrines and normal plasma levels of catecholamines could be associated with a pheochromocytoma in the case of an episodic release of catecholamines and a continuous leakage of normetanephrine (Goldstein et al. 2004). In this group of patients, it is worth noticing how functional data may be useful in distinguishing between a normal adrenal and a pheochomocytoma. Many studies have compared the accuracy of CT, MRI and ${ }^{131}$ I-MIBG scintigraphy in the diagnosis of suspected pheochromocytomas (Maurea et al. 1993, 1996, Van Gils et al. 1994, Elgazzar et al. 1995, Freitas 1995). Others have reported results with ${ }^{123}$ I-MIBG, which enjoys the advantages of having an energy more suitable for the $\gamma$ camera, a shorter half-life than ${ }^{131} \mathrm{I}$ and the absence of $\beta$ emission (Maurea et al. 1995). High sensitivity and specificity $(100 \%)$ values have been reported for ${ }^{123}$ I-MIBG (Furuta et al. 1999). However, the problem of normal adrenal medullary tissue, which frequently gives an apparently positive ${ }^{123}$ I-MIBG scan (Maurea et al. 1995), has not, to our knowledge, been fully clarified in the literature.

The aim of this study was to assess the usefulness of a scoring system, based on different uptakes of the radiopharmaceutical, in improving the accuracy of MIBG scintigraphy in patients with either adrenal or extra-adrenal pheochromocytomas. In particular, the purpose was to identify a score that could be useful in distiguishing pheochromocytoma from the physiological uptake of the adrenals.

\section{Materials and methods}

Charts from 67 consecutive patients who underwent ${ }^{123}$ I-MIBG scintigraphy from 1991 to 2004 were reviewed: $29(43.3 \%)$ were males and $38(56.7 \%)$ were females with a median age of 48 years (range 14-80 years). ${ }^{123}$ I-MIBG might be preferred to ${ }^{131}$ I-MIBG because of its superior dosimetric characteristics, its shorter physical half-life (13 h vs 8 days) and lack of $\beta$ emission (Hanson et al. 1991, Maurea et al. 1993, 1996). Furthermore, the adsorbed dose from a given activity of ${ }^{123} \mathrm{I}$ is $1 / 80$ to $1 / 100$ compared with that from ${ }^{131}$ I-MIBG (Berman et al. 1975).

Three major clinical indications for performing ${ }^{123}$ I-MIBG scintigraphy have been identified (Table 1). (1) Severe arterial hypertension or paroxysm $(n=49)$ and adrenal or extra-adrenal mass at CT or MRI associated with an increased level of urinary catecholamines (UC) and/or fractionated urine

Table 1 Patients grouped according to reasons for performing MIBG scintigraphy

No. of patients Clinical indications Other characteristics of the patients

\begin{tabular}{|c|c|c|}
\hline 49 & Severe arterial hypertension or paroxysms & $\begin{array}{l}\text { Adrenal/extra-adrenal mass at CT scan or MRI and UC and/or UM } \\
\text { elevation }(n=47) \text {; adrenal mass }(n=2) \text { at CT scan, without UC } \\
\text { elevation }\end{array}$ \\
\hline \multirow[t]{4}{*}{14} & Familial syndromes & $\begin{array}{l}\text { MEN2A }(n=6) \text { all submitted to total thyroidectomy for MTC, with } \\
\text { slight UC elevation, hypertension }(3 / 6) \text { and adrenal mass }(5 / 6) \text { or } \\
\text { enlargement }(1 / 6)\end{array}$ \\
\hline & & $\begin{array}{l}\text { NF1 }(n=2) \text { with hypertensive crisis, monolateral adrenal mass and } \\
\text { elevated UC and UM }\end{array}$ \\
\hline & & $\begin{array}{l}\text { VHL }(n=4) \text { with hypertensive crisis, elevated UC and UM, bilateral } \\
(2 / 4) \text { or monolateral }(2 / 4) \text { adrenal mass. } 1 / 4 \text { cases were identified } \\
\text { after genetic study of the family and revealed a somatic mosaicism } \\
\text { (Murgia et al. } 2000)\end{array}$ \\
\hline & & Isolated MTC $(n=2)$ and adrenal enlargement \\
\hline 4 & Incidentally discovered adrenal masses & $\begin{array}{l}\text { Slight }(n=3) \text { or marked }(n=1) \text { increase of UC, CT scan }(n=3) \text { or } \\
\text { MRI }(n=1) \text { suggesting a pheochromocytoma }\end{array}$ \\
\hline
\end{tabular}

$\mathrm{UC}=$ urinary catecholamines, $\mathrm{UM}=$ urinary metanephrines, $\mathrm{MEN}=$ multiple endocrine neoplasia, $\mathrm{MTC}=$ medullary carcinoma of the thyroid gland, $\mathrm{VHL}=$ von Hippel-Lindau syndrome, NF1 = neurofibromatosis type 1. 
metanephrines (FUM). In two cases out of 49, an ${ }^{123}$ I-MIBG scan was performed without elevation of urinary catecholamines (metanephrines were not measured) because of an adrenal mass and persistent severe hypertension. (2) Patients with familial syndromes $(n=14)$ presenting adrenal masses and increased UC and/or FUM. (3) Patients with incidentally discovered adrenal masses $(n=4)$ and slight or marked increase of UC and/or FUM.

Twenty four-hour FUM or urinary catecholamine measurements were obtained in all patients since 2000, while urinary catecholamines were determined in the remaining patients. Abdominal CT scan was performed in all patients and, moreover, $20(29.8 \%)$ patients underwent MRI between 10 to 24 days (median 14 days) before MIBG scintigraphy. Premenopausal women who were pregnant were excluded. Informed consent was obtained from each patient.

Medications that could interfere with MIBG uptake (i.e. calcium antagonist, labetalol, reserpine, tricyclic antidepressant) were discontinued for the appropriate time (opioids and sympathicomimetics for 7-14 days, tricyclic antidepressant for 7-21 days, antihypertensive/cardiovascular agents for 14-21 days and antipsychotics for 21-28 days).

Patients ( $n=65$ out of 67 ) received orally ten drops of Lugol's solution (potassium iodide 10\% and iodine $5 \%$ ), three times a day for a total of 6 days starting on the day before injection of the radiopharmaceutical or potassium perchlorate $(200 \mathrm{mg}$ orally at least $30 \mathrm{~min}$ before administration of MIBG, $n=2$ out of 67 patients) to prevent thyroid uptake of unbound iodine.

${ }^{123}$ I-MIBG (300-370 MBq; GE Healthcare Biosciences, Saluggia (VC), Italy) was administered by slow intravenous injection (at least $5 \mathrm{~min}$ ) in a pheripheral vein, flushed with saline.

In two patients (one female of 15 years and one male of 14 years; median age 14.5 years), the activity administered was calculated on the basis of a reference dose for an adult, scaled to body weight according to the schedule proposed by the European Association of Nuclear Medicine Pediatric Task group (Piepsz et al. 1990). All patients were encouraged to drink fluids following the MIBG injection and to void frequently. Anterior and posterior total body scans were acquired 4 and $24 \mathrm{~h}$ after ${ }^{123} \mathrm{I}$-MIBG injection. Spot images (about $350-400$ kcounts) of the suspicious areas were obtained occasionally. Images of kidneys (using ${ }^{99 \mathrm{~m}}$ Tc-diethylenetriaminepentacetic acid (DTPA)) or liver (using ${ }^{99 \mathrm{~m}}$ Tc-Albures) were frequently obtained for a better localization of the tumor. A single-headed, large field-of-view $\gamma$ camera (Sopha Medical DSX; GE Healthcare TechnologiesWaukesha, WI, USA) equipped with a low-energy, high-resolution collimator was used.

Two experienced nuclear medicine physicians reviewed the images independently. The intensity of adrenal MIBG uptake compared with hepatic uptake was evaluated at $24 \mathrm{~h}$.

The results were scored from 1 to 4 as follows: score 1, uptake absent or uptake less intense than in the liver, score 2, uptake equal to the liver, score 3, uptake moderately more intense than in the liver and score 4, uptake markedly more intense than in the liver. Scintigraphies were classified as positive in the case of an extra-adrenal focal uptake, an adrenal enlargement together with non-homogeneous uptake or an adrenal uptake more intense than in the liver (score 3-4). The remaining scans were classified as negative (score 1) or doubtful (score 2).

True positive (TP), true negative (TN), false positive $(\mathrm{FP})$ and false negative $(\mathrm{FN})$ results were established according to clinical, biochemical and histological data and on the basis of a long-term follow-up.

Sensitivity was defined as $(\mathrm{TP}) /(\mathrm{TP}+\mathrm{FN})$, specificity as $(\mathrm{TN}) /(\mathrm{TN}+\mathrm{FP})$, positive predictive value (PPV) as (TP)/(TP $+\mathrm{FP})$, negative predictive value (NPV) as (TN)/(TN + FN), and accuracy as $(\mathrm{TN}+\mathrm{TP})$ over all patients.

\section{Results}

Forty-eight $(71.6 \%)$ patients thought to be affected by pheochromocytoma/paraganglioma underwent surgery followed by histological examination of the removed tumor (Table 2) and long-term follow-up. The largest mass was $12 \mathrm{~cm}$ and the smallest $1 \mathrm{~cm}$ in diameter (median $4.53 \mathrm{~cm}$ ). Initially, one of the patients (one out of 48) from the incidentaloma group was considered as having a pheochromocytoma because of a $2.5 \mathrm{~cm}$ (CT) adrenal enlargement and a slight increase in urinary catecholamines. ${ }^{123}$ I-MIBG showed an uptake less intense than in the liver (score 1), thus this was considered to be a true negative in the present study. Histological examination of the removed tumor revealed a cortical adenoma.

The percentage of extra-adrenal uptake of ${ }^{123} \mathrm{I}$ MIBG (five out of $67 ; 10.63 \%$ ) was very close to previously published data (Werbel \& Ober 1995). One out of five was an extra-adrenal pheochromocytoma 
Table 2 Outcome of procedures

\begin{tabular}{|c|c|c|c|c|}
\hline Group & Referred to surgery & Monolateral PH & Bilateral PH & Others \\
\hline Severe paroxysm or hypertension $(n=49)$ & $36 / 49$ & $29 / 36$ & $2 / 36$ & 5/36 PG \\
\hline Familial syndromes $(n=14)$ & $9 / 14$ & $\begin{array}{l}\text { 8/9 } \\
\text { 3/9 MEN2A } \\
\text { 2/9 NF1 } \\
\text { 3/9 VHL }\end{array}$ & $\begin{array}{l}1 / 9 \\
1 \text { MEN2A }\end{array}$ & $0 / 9$ \\
\hline Incidentally discovered masses $(n=4)$ & $3 / 4$ & $2 / 3$ & $0 / 3$ & $1 / 3 \mathrm{CA}$ \\
\hline Total $(n=67)$ & $48 / 67(71.6 \%)$ & $39 / 48$ & $3 / 48$ & $6 / 48$ \\
\hline Not referred to surgery & $19 / 67(28.4 \%)$ & & & \\
\hline
\end{tabular}

$\mathrm{PH}=$ pheochromocytoma, $\mathrm{PG}=$ paraganglioma, $\mathrm{CA}=$ cortical adenoma .

occurring at the bladder, three out of five were in the para-adrenal area and the last (one out of five) was localized near to the inferior mesenteric artery. The largest extra-adrenal pheochromocytoma was $8 \mathrm{~cm}$ and the smallest $2.5 \mathrm{~cm}$ in diameter (median $4.3 \mathrm{~cm}$ ). None of the paragangliomas have proved to be malignant to date.

The remaining $19(28.4 \%)$ patients, not referred to surgery, underwent long-term (range 1-14 years, median 9.25 years) follow-up. Imaging (CT or MRI) performed in this group of patients, clinical examinations and biochemical investigations have shown no sign of malignancy to date. In two cases, a slight increase of urine catecholamines was observed 3 years after a negative ${ }^{123}$ I-MIBG scan. No increase in adrenal mass diameter was observed by MRI in either case and no symptoms were present. Repeated metanephrine levels were normalized and, at present, both patients are considered true negatives. A case of an asymptomatic adrenal mass revealed by CT in $1998(1.6 \mathrm{~cm})$ with an uptake of ${ }^{123}$ I-MIBG scoring 1 is still stable $(1.5 \mathrm{~cm}$ at CT in 2004) and symptom free.

Findings of MIBG scintigraphy according to the scoring system for each group are reported in Table 3. For each patient the higher uptake of the two adrenals was considered. In all monolateral cases considered positive (score 3-4), the contralateral uptake was negative (scoring 1 or 2 ). Two out of three patients with bilateral masses (indicated in Table 3 by an asterisk) had an adrenal uptake of grade 3 or 4 and a contralateral uptake of grade 3 or 4 . In the remaining case (one out of three) there was an adrenal mass scoring 4 and a contralateral mass that revealed an adrenal enlargement together with non-homogeneous uptake of ${ }^{123} \mathrm{I}-\mathrm{MIBG}$.

Overall there were 13 patients who scored 1,12 patients who scored 2, 10 patients who scored 3, 27 patients who scored 4 and five extra-adrenal uptakes.

Forty-three patients (27 scoring $4+10$ scoring 3 + five extra-adrenal uptakes + one significant adrenal enlargement together with non-homogeneous uptake of ${ }^{123}$ I-MIBG) were considered true positives, 20 (13 scoring $1+12$ scoring 2 -four false negative - one significant adrenal enlargement together with non-homogeneous uptake of ${ }^{123} \mathrm{I}$ MIBG considered true positives) were considered true negatives, four patients (three from the hypertensive group + one from the incidentaloma group) with a score of 1-2 but with a surgically and histologically proved pheochromocytoma were

Table 3 Number of patients scored for each group

\begin{tabular}{|c|c|c|c|c|c|c|}
\hline Group & Score 1 & Score 2 & Score 3 & Score 4 & $\begin{array}{c}\text { Extra-adrenal } \\
\text { uptake }\end{array}$ & Total \\
\hline Severe paroxysm or hypertension & $7\left(+1^{*}\right)$ & 10 & 7 & $20\left(+1^{\star}\right)$ & 5 & 49 \\
\hline Familial syndromes & 3 & 2 & 3 & 6 & 0 & 14 \\
\hline MEN2A & 0 & 2 & $1\left(+1^{\star}\right)$ & 3 & 0 & 6 \\
\hline VHL & 1 & 0 & 2 & 1 & 0 & 4 \\
\hline NF1 & 0 & 0 & 0 & 2 & 0 & 2 \\
\hline MTC & 2 & 0 & 0 & 0 & 0 & 2 \\
\hline Incidentaloma & 3 & 0 & 0 & 1 & 0 & 4 \\
\hline Total & 13 & 12 & 10 & 27 & 5 & 67 \\
\hline
\end{tabular}

MTC = isolated medullary carcinoma of the thyroid gland and adrenal enlargement, *bilateral pheochromocytoma. 
Table 4 Score results

\begin{tabular}{lccrr}
\hline & TP & TN & FP & FN \\
\hline Score 1 & - & $10\left(13-2^{\mathrm{A}}=10\right)$ & - & 2 \\
Score 2 & - & $10\left(12-2^{\mathrm{A}}-1^{\mathrm{B}}=10\right)$ & - & 12 \\
Score 3 & 10 & - & - & - \\
Score 4 & 27 & - & - & - \\
Extra-adrenal uptake & 5 & - & - & - \\
Non-homogeneous enlargement & 1 & - & - & - \\
Total & 43 & 20 & 0 & - \\
\hline
\end{tabular}

${ }^{A}=$ false negatives, ${ }^{B}=$ adrenal enlargements together with non-homogeneous uptake of I-MIBG.

considered false negatives. No false positives were observed (Table 4).

The sensitivity of the proposed method was $91.5 \%$. The specificity and PPV were $100 \%$, the NPV value $83.3 \%$ and the accuracy $94 \%$. Cohen's $\kappa$ score between two experienced nuclear medicine physicians was $81 \% \quad(P<0.001)$. An agreement was reached in every discordant case. The nine discordant cases had a final score of $1(n=1), 2$ $(n=6)$ and $4(n=2)$. In all but one case out of six scoring 2, the two physicians independently assigned a score of 1 or 2 . In only one out of six cases scoring 2 did one physician score the mass 2 while the other scored it 3 .

\section{Discussion}

CT or MRI represent the first diagnostic step in the localization of phaeochromocytoma (Van Gils et al. 1994), but frequently the nature of the identified adrenal mass remains to be clarified (Berglund et al. 2001). Furthermore, the functional meaning of suspected paragangliomas or metastatic malignant masses can be difficult to obtain with $\mathrm{CT}$ or MRI and it has been demonstrated that when postoperative changes are present (Pacak et al. 2001) the sensitivity of both MRI and CT decreases.

On the other hand, when dealing with sporadic phaeochromocytomas, especially when plasma and urinary metanephrines are elevated, MIBG scintigraphy contributes little additional information to that obtained by a clearly positive and unilateral CT or MRI (Taïeb et al. 2004). Furthermore, when managing the familial forms, MIBG scintigraphy seems to lack specificity, as demonstrated in a study concerning MEN2A (De Graaf et al. 2000).

High sensitivity and specificity values have been reported in the literature for MIBG scintigraphy (Table 5). However, as observed by other authors (Maurea et al. 1995), normal adrenal medullary tissue frequently gives an apparently positive scan with ${ }^{123}$ I-MIBG. Indeed, normaI adrenals are visualized in $2 \%$ of cases at $24 \mathrm{~h}$ and in $16 \%$ of cases at $48 \mathrm{~h}$ for ${ }^{131}$ I-MIBG (Lindbery et al. 1988 , Nakajo et al. 1983) and even more frequently using ${ }^{123} \mathrm{I}-$ MIBG (Shapiro et al. 2001). Possible explanations for the variable uptake of normal adrenals may be an increased number of storage granules (Bomanji et al. 1987) and/or the increased size of the gland. Nowadays the rapid improvement and diffusion of morphological imaging techniques (echography, CT or MRI) leads to detection of a greater number of slightly 'enlarged' adrenals. When dealing with functional imaging a decision has to be made as to whether the uptake of ${ }^{123} \mathrm{I}-\mathrm{MIBG}$, revealed in those adrenals, relates to a physiological uptake, a hyperplasia or a pheochromocytoma. Although diffuse adrenal medullary hyperplasia is a rare

Table 5 Sensitivity and specificity values of MIBG scintigraphy (various authors)

\begin{tabular}{|c|c|c|c|c|}
\hline Sensitivity (\%) & Specificity (\%) & ${ }^{131}$ I or ${ }^{123}$ I-MIBG & Cases & Reference \\
\hline 87.4 & 99 & Overall & 400 & Shapiro et al. 1985 \\
\hline 88.5 & - & $A=66.1 \%, B=33.9 \%$ & 174 & Mannelli et al. 1999 \\
\hline 88 & 89 & Overall & 64 & Berglund et al. 2001 \\
\hline 85 & $>95$ & Overall & $\mathrm{R}$ & Shapiro et al. 1995 \\
\hline 85.7 & 100 & A & 29 & Furuta et al. 1999 \\
\hline 90 & 100 & $\mathrm{~B}$ & 16 & Furuta et al. 1999 \\
\hline
\end{tabular}

Overall $={ }^{131} \mathrm{I}-\mathrm{MIBG}$ and ${ }^{123} \mathrm{I}-\mathrm{MIBG}, \mathrm{A}={ }^{131} \mathrm{I}-\mathrm{MIBG}, \mathrm{B}={ }^{123} \mathrm{I}-\mathrm{MIBG}, \mathrm{R}=$ review. 
Table 6 Details of patients scoring 2

\begin{tabular}{|c|c|c|c|c|c|c|c|}
\hline Case no. & Sex & Age (years) & LAU & RAU & Results & Symptoms & FU \\
\hline 1 & $\mathrm{~F}$ & 44 & 1 & 2 & $\mathrm{TN}$ & $\mathrm{AH}, \mathrm{H}$ & 8 \\
\hline 2 & $\mathrm{~F}$ & 55 & 1 & 2 & $\mathrm{TN}$ & $\mathrm{AH}$ & 13 \\
\hline 3 & $\mathrm{~F}$ & 47 & 1 & 2 & $\mathrm{TN}$ & $\mathrm{AH}$ & 9 \\
\hline 4 & M & 59 & 1 & 2 & $\mathrm{TN}$ & $\mathrm{AH}$ & 5 \\
\hline 5 & $M$ & 47 & 2 & 1 & $\mathrm{TN}$ & $\mathrm{AH}$ & 13 \\
\hline 6 & M & 68 & 2 & 1 & $\mathrm{TN}$ & $\mathrm{AH}, \mathrm{S}$ & 8 \\
\hline 7 & $\mathrm{~F}$ & 56 & 2 & 2 & $\mathrm{TN}$ & $\mathrm{AH}$ & 9 \\
\hline 8 & $\mathrm{~F}$ & 45 & 2 & 2 & $\mathrm{TN}$ & $\mathrm{AH}$ & 14 \\
\hline 9 & $\mathrm{~F}$ & 18 & 2 & 1 & $\mathrm{TN}$ & $\mathrm{AH}$ & 13 \\
\hline 10 & M & 65 & 4 & 2 & TP & $\mathrm{AH}, \mathrm{P}$ & 12 \\
\hline 11 & $\mathrm{~F}$ & 47 & 3 & 2 & TP & $\mathrm{AH}$ & 10 \\
\hline 12 & $M$ & 48 & 4 & 2 & TP & $\mathrm{AH}, \mathrm{P}$ & 8 \\
\hline 13 & $\mathrm{~F}$ & 53 & 4 & 2 & TP & $\mathrm{AH}$ & 7 \\
\hline 14 & $\mathrm{~F}$ & 29 & 4 & 2 & TP & $\mathrm{AH}, \mathrm{H}$ & 10 \\
\hline 15 & $\mathrm{~F}$ & 31 & 1 & 2 & TP (EXTRA) & $\mathrm{AH}$ & 8 \\
\hline 16 & $M$ & 43 & 2 & 2 & TP (EXTRA) & $\mathrm{AH}, \mathrm{P}$ & 13 \\
\hline 17 & M & 14 & 1 & 2 & TP (EXTRA) & $\mathrm{AH}, \mathrm{P}$ & 10 \\
\hline 18 & M & 41 & 2 & 1 & $\mathrm{TP}-\mathrm{BIG}$ & $\mathrm{AH}, \mathrm{P}$ & 5 \\
\hline 19 & $\mathrm{~F}$ & 44 & 2 & 1 & $\mathrm{FN}$ & $\mathrm{AH}$ & 1 \\
\hline 20 & $\mathrm{~F}$ & 70 & 2 & 2 & FN - horseshoe & $\mathrm{AH}$ & 8 \\
\hline
\end{tabular}

$\mathrm{LAU}=$ uptake of left adrenal, $\mathrm{RAU}=$ uptake of right adrenal, EXTRA $=$ extra adrenal uptake, $\mathrm{BIG}=$ enlarged adrenal and non-homogeneous uptake, $\mathrm{AH}=$ arterial hypertension, $\mathrm{P}=$ paroxysm, $\mathrm{S}=$ sweating, $\mathrm{H}=$ headache, $\mathrm{FU}=$ follow-up (years).

condition (Babington et al. 2000), frequently related to multiple neoplasia type II, it is a possible source of false positive uptake using MIBG.

It is therefore of some interest to discuss separately the patients presenting a doubtful uptake score 2 (equal to the liver) because, in our opinion, this is probably where the score could be potentially useful.

All adrenals scoring $2(n=20)$ are shown in Table 6 including patients with a contralateral uptake scoring $3(n=1)$ or $4(n=4)$ considered true positives, patients with an extra adrenal uptake together with an adrenal uptake scoring $2(n=3)$ and two false negative results.

All but one patient (considered false negative after 1 year) scoring 2 were followed-up for a long period (9.2 years). Among true positive scintigraphies, CT or MRI, clinical examinations and biochemical investigations have shown no sign of malignancy in the contralateral gland scoring 2 to date. In this group of patients, the proposed score has correctly characterized a true positive uptake (scoring 3 or 4) and a negative contralateral uptake (scoring 2). Patient number 18 (Table 6) showed an uptake scoring 2 in the left adrenal but it was considered true positive because of an adrenal enlargement together with non-homogeneous uptake. The surgically removed tumor was $5.3 \mathrm{~cm}$ in diameter and presented central necrosis. Another three patients (nos 15, 16 and 17 in Table 6) showed an extra-adrenal uptake and a monolateral $(n=2)$ or bilateral $(n=1)$ uptake scoring 2 . The extraadrenal masses removed measured respectively $3 \mathrm{~cm}$ (bladder), $8 \mathrm{~cm}$ (inferior mesenteric artery) and $4 \mathrm{~cm}$ (para-adrenal) in diameter. A long follow-up (median 10 years) in this group of patients has shown no adrenal masses to date.

Among the other true positive studies (with a monolateral uptake scoring 3 or 4 and a contralateral uptake scoring 1), uptake 3 or 4 precisely characterized the adrenal mass as a pheochromocytoma as confirmed in all cases by surgery. The median diameter of the removed mass was $4.9 \mathrm{~cm}$ in this group of patients.

Two patients (nos 2 and 7) listed in Table 6 as true negatives, scoring 2 , had adrenal lesions measuring more than $2 \mathrm{~cm}$ in diameter. Nevertheless, at present (after 13 and 8 years of follow-up respectively), no increase in metanephrines has been found in either patient and arterial hypertension is under control. Both, at present, are considered true negatives. Of the remaining patients scoring 2 and considered true negatives (nos 1, 3, 4, 5, 6, 8 and 9 in Table 6), one case (no. 8 in Table 6 with a bilateral uptake scoring 2 thus considered true negative) has recently shown a slight increase in urinary catecholamines. In this patient, MRI has not revealed adrenal masses and FUM are normal at present. 
Among false negative results $(n=4)$, two patients showed a monolateral $(n=1)$ or bilateral $(n=2)$ uptake scoring 2. In one case (no. 20 in Table 6), echography revealed a horseshoe kidney while in the other (no. 19), thought to have hyperplasia of one adrenal, severe paroxysm and elevated urine metanephrines suggested a pheochromocytoma. The surgically removed left adrenal showed a $3 \mathrm{~cm}$ pheochromocytoma. In the other two patients with false negative scintigraphy (both scoring 1), an intra-adrenal pheochromocytoma was histologically confirmed; the extensive colliquative necrosis within the mass $(4 \mathrm{~cm}$ in diameter) justified the false negative result in one case, while the low uptake remains unexplained in the other patient.

Special attention should be given to the fact that a mild (score 2) uptake, even if highly suggestive of a normal pattern or mild hyperplasia, could be associated with unilateral pheochromocytoma as shown by false negative results. On the other hand, among doubtful scintigraphies (scoring 2), the proposed method correctly discriminated pheochromocytoma from normal adrenal (or hyperplasia) in 18 out of 20 patients. Nevertheless, despite the good $\kappa$ scores of agreement between two experienced nuclear medicine physicians $(81 \%)$, it is to be taken into account that a nuclear medicine physician who is not used to ${ }^{123} \mathrm{I}-\mathrm{MIBG}$ could experience some difficulties in assigning a score of 2 (as demonstrated by the six discordant opinions on six patients scoring 2). Finally, we must point out that 15 adrenals scoring 2 were located on the right side while only nine were on the left adrenal. This may be due to a high uptake by the liver which increases the count on the right side. On the other hand, the liver shadow could also obscure the right adrenal in some cases (as shown in Fig. 1). Thus, especially in the case of a high uptake of the radiopharmaceutical
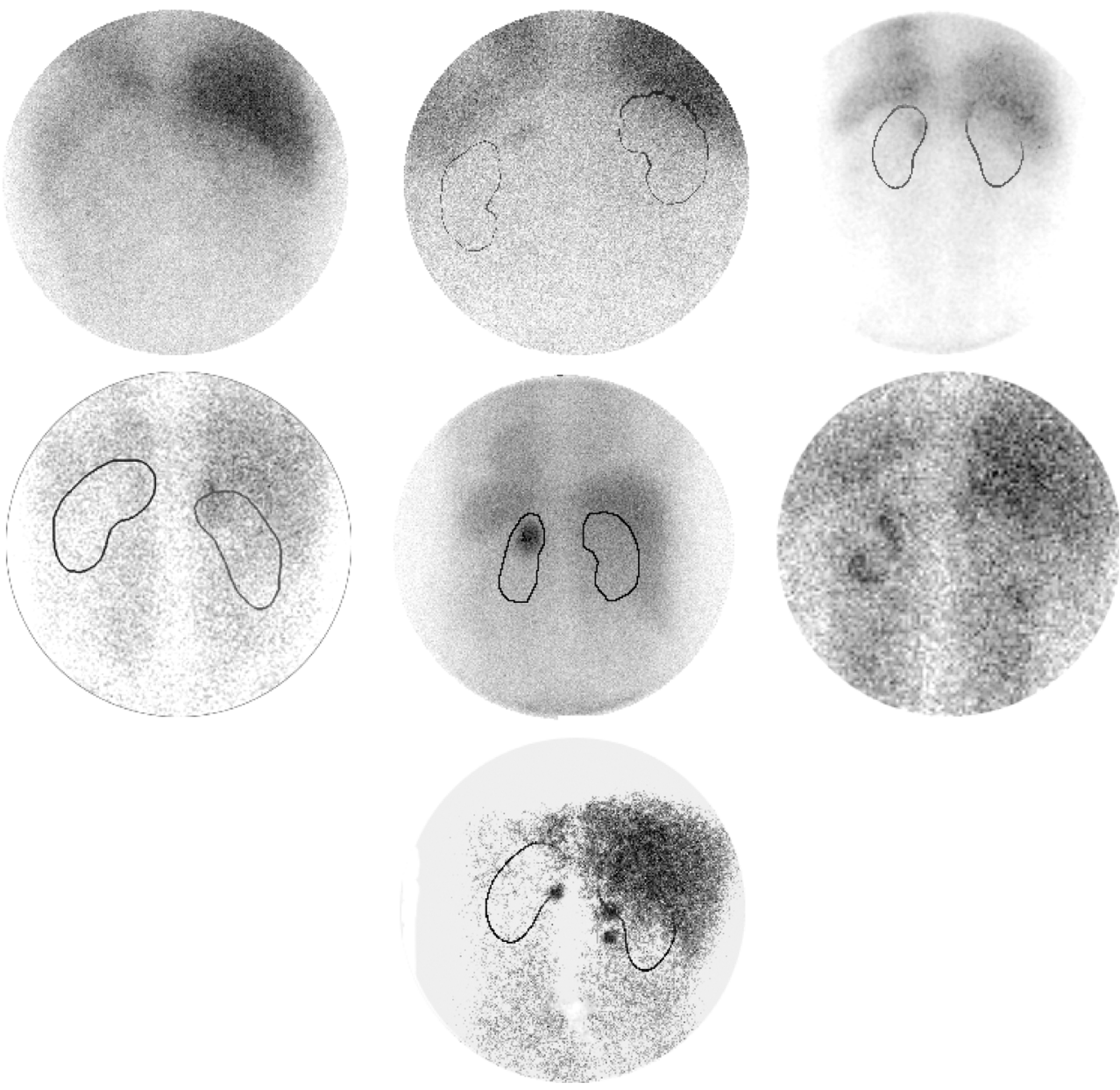

Figure 1 Example images of the proposed scoring system, extra-adrenal uptake and adrenal enlargements together with nonhomogeneous uptake. 
by the liver, special attention should be paid when dealing with a mild uptake (score 2) or an absent uptake in the right adrenal.

\section{Acknowledgements}

Early results of this work were presented at the 6th Congress of the Italian Association of Nuclear Medicine 15-19 November 2002, Genoa, Italy and at the 6th European Congress of Endocrinology 26-30 April 2003, Lyon, France. There is no conflict of interest prejudicing the impartiality of this study.

\section{References}

Babington CKY, Tony KLL, Tse TW, Tsang MW \& Chan JCS 2000 Sporadic bilateral adrenal medullary hyperplasia: apparent false positive MIBG scan and expected MRI findings. European Journal of Radiology 36 28-31.

Berglund AS, Hulthen UL, Manhem P, Thorsson O, Wollmer P \& Tornquist C 2001 Metaiodobenzylguanidine (MIBG) scintigraphy and computed tomography (CT) in clinical practice. Primary and secondary evaluation for localization of phaeochromocytomas. Journal of Internal Medicine 249 247-251.

Berman M, Braverman LE, Burke J, De Groot L, McCormak KR, Oddie TH, Rohrer RH, Wellman HN \& Smith EM 1975 MIRD dose estimate report no. 5. Summary of current radiation dose estimates to humans from ${ }^{123} \mathrm{I},{ }^{124} \mathrm{I},{ }^{125} \mathrm{I},{ }^{126} \mathrm{I},{ }^{130} \mathrm{I},{ }^{131} \mathrm{I}$, and ${ }^{132} \mathrm{I}$ as sodium iodide. Journal of Nuclear Medicine 16 857-860.

Bomanji J, Levison DA, Flatman WD, Horne T, Bouloux PMG, Ross G, Britton KE \& Besser GM 1987 Uptake of iodine-123 MIBG by pheochromocytomas, paragangliomas, and neuroblastomas: a histopathological comparison. Journal of Nuclear Medicine 28 973-978.

De Graaf JS, Dullaart RP, Kok T, Piers DA \& Zwierstra RP 2000 Limited role of meta-iodobenzylguanidine scintigraphy in imaging phaeochromocytoma in patients with multiple endocrine neoplasia type II. European Journal of Surgery 166 289-292.

Eisenhofer G, Lenders JW, Linehan WM, Walther MM, Goldstein DS \& Keiser HR 1999 Plasma normetanephrine and metanephrine for detecting pheochromocytoma in von Hippel-Lindau disease and multiple endocrine neoplasia type 2. New England Journal of Medicine $\mathbf{3 4 0}$ 1872-1879.

Elgazzar AH, Gelfand MJ, Washburn LC, Clark J, Nagaraj N, Cummings D, Hughes J \& Maxon HR 3rd 1995 I-123 MIBG scintigraphy in adults. A report of clinical experience. Clinical Nuclear Medicine 20 147-152.
Freitas JE 1995 Adrenal cortical and medullary imaging. Seminars in Nuclear Medicine 25 235-250.

Furuta N, Kiyota H, Yoshigoe F, Hasegawa N \& Ohishi Y 1999 Diagnosis of pheochromocytoma using [123I]compared with [131I]-metaiodobenzylguanidine scintigraphy. International Journal of Urology 6 119-124.

Goldstein DS, Eisenhofer G, Flynn JA, Wand G \& Pacak K 2004 Diagnosis and localization of pheochromocytoma. Hypertension 43 907-910.

Hanson WH, Feldman JM, Beam CA, Leight GS \& Coleman RE 1991 Iodine 131-labeled metaiodobenzylguanidine scintigraphy and biochemical analyses in suspected pheochromocytoma. Archives of Internal Medicine $\mathbf{1 5 1}$ 1397-1402.

Lenders JWM, Eisenhofer G, Mannelli M \& Pacak K 2005 Phaeochromocytoma. Lancet 366 665-675.

Lindbery S, Fjalling M, Jacobsson L, Jansson S \& Tisell LE 1988 Methodology and dosimetry in adrenal medullary imaging with iodine-131 MIBG. Journal of Nuclear Medicine 29 1638-1643.

Mannelli M, Ianni L, Cilotti A \& Conti A 1999 Pheochromocytoma in Italy: a multicentric retrospective study. European Journal of Endocrinology 141 619-624.

Maurea S, Cuocolo A, Reynolds JC, Tumeh SS, Begley MG, Linehan WM, Norton JA, Walther MM, Keiser HR \& Neumann RD 1993 Iodine-131-metaiodobenzylguanidine scintigraphy in preoperative and postoperative evaluation of paragangliomas: comparison with CT and MRI. Journal of Nuclear Medicine 34 173-179.

Maurea S, Lastoria S, Cuocolo A, Celentano L \& Salvatore M 1995 The diagnosis of nonfunctioning pheochromocytoma. The role of I-123 MIBG imaging. Clinical Nuclear Medicine 20 22-24.

Maurea S, Cuocolo A, Reynolds JC, Neumann RD \& Salvatore M 1996 Diagnostic imaging in patients with paragangliomas. Computed tomography, magnetic resonance and MIBG scintigraphy comparison. Quarterly Journal of Nuclear Medicine 40 365-371.

Murgia A, Martella M, Vinanzi C, Polli R, Perilongo G \& Opocher G 2000 Somatic mosaicism in von Hippel-Lindau Disease. Human Mutation 15114.

Nakajo M, Shapiro B, Copp J, Kalff V, Gross MD, Sisson JC \& Beierwaltes WH 1983 The normal and abnormal distribution of the adrenomedullary imaging agent $\mathrm{m}$-[I-131]iodobenzylguanidine (I-131 MIBG) in man: evaluation by scintigraphy. Journal of Nuclear Medicine 24 672-682.

Pacak K, Goldstein DS, Doppman JL, Shulkin BL, Udelsman R \& Eisenhofer G 2001 A 'pheo' lurks: novel approaches for locating occult pheochromocytoma. Journal of Clinical Endocrinology and Metabolism $\mathbf{8 6}$ 3641-3646.

Piepsz A, Hahn K, Roca I, Ciofetta G, Toth G, Gordon I, Kolinska J \& Gwidlet J 1990 A radiopharmaceuticals schedule for imaging in paediatrics. Task Group European Association of Nuclear Medicine. European Journal of Nuclear Medicine 17 127-129. 
Shapiro B, Copp JE, Sisson JC, Eyre PL, Wallis J \& Beierwalters WH 1985 Iodine-131

metaiodobenzylguanidine for the locating of suspected pheochromocytoma: experience in 400 cases. Journal of Nuclear Medicine 26 576-585.

Shapiro B, Sisson JC, Shulkin BL, Gross MD \& Zempel S 1995 The current status of meta-iodobenzylguanidine and related agents for the diagnosis of neuro-endocrine tumors. Quarterly Journal of Nuclear Medicine 39 3-8.

Shapiro B, Gross MD \& Shulkin B 2001 Radioisotope diagnosis and therapy of malignant pheochromocytoma. Trends in Endocrinology and Metabolism 12 469-475.
Taïeb D, Sebag F, Hubbard JG, Mundler O, Henry JF \& Conte-Devolx B 2004 Does iodine-131 metaiodobenzylguanidine (MIBG) scintigraphy have an impact on the management of sporadic and familial phaeochromocytoma? Clinical Endocrinology 61 102-108.

Van Gils AP, van Erkel AR, Falke TH \& Pauwels EK 1994 Magnetic resonance imaging or metaiodobenzylguanidine scintigraphy for the demonstration of paragangliomas? Correlations and disparities. European Journal of Nuclear Medicine 21 239-253.

Werbel SS \& Ober KP 1995 Pheochromocytoma. Update on diagnosis, localization, and management. Medical Clinics of North America 79 131-153. 
